\title{
Notas sobre o "múltiplo" na primeira Crítica
}

\author{
U birajara $R$ ancan de Azevedo $M$ arques \\ Unesp
}

resumo examina-se aqui uma solução de tipo "idealista" para o problema da possibilidade do múltiplo, a qual, assim parece, levaria à exigência da admissão de um espaço e um tempo inatos. Eliminando-se qualquer pretensa concessão inatista por parte de Kant, porém, observa-se que o resultado alcançado, neste caso, favorece a originalidade do idealismo transcendental.

palavras-chave múltiplo - a priori - inato - adquirido - aquisição originária

0 múltiplo, cujo sentido passa por "evidente" [selbstverständlich], e "do qual $K$ ant fala muitas vezes (... ) sem nunca o caracterizar mais a fundo" (VAIHINGER, 1970, vol. 2, p. 224), na justa observação de Hans Vaihinger, surge propriamente no enredo da noção de síntese, embora já esteja nomeado desde o início da “Estética”. A mesma síntese, por sinal, e em função dela o múltiplo, aparece também de forma algo abrupta, valendo, por isto, a nota de Luigi Scaravelli:

(... ) a síntese não foi ainda examinada. É este um dos casos nos quais

(...) K ant emprega (...) argumentos ou concepções que só muito depois se tornarão inteligíveis (...) fala aqui [trata-se do $§ 10$ da C rítica da raz ão pura] da síntese de modo tão amplo, tendo para si que o leitor não encontre dificuldade em aceitar o que aí é dito (SCAR AVELLI, 1973, p. 223).

R ecebido em janeiro de 2005. A ceito em maio de 2005.

doispontos, Curitiba, São Carlos, vol. 2, n. 2, p.145-156, outubro, 2005 
D o mesmo modo se pronuncia ainda H ermann M örchen, para quem "o conceito de múltiplo é em Kant tão ambígüo [mehrdeutig] quanto o de síntese" (M Ö R CHEN , 1970, p. 61).

Tal como aparece no início do § 1 da "Estética” - "(...) denomino (...) forma do fenômeno aquilo que faz com que o múltiplo do fenômeno possa ser ordenado em certas relações" (KAN T, 1983, p. 39; id., 1974, B 341) - , o múltiplo é o modo de representação da matéria, como a unidade 0 é da forma. Serão justas, pois, as palavras de 0 swaldo $M$ arket:

Se consideramos mais de perto o uso da palavra ["M annigfaltig"], observamos que ela é justamente o portador da única explicação do conteúdo da matéria. Se a matéria é de fato descrita como o que corresponde à sensação, então nós devemos admitir que ela é em si mesma um $x$, que encerra uma multiplicidade, isto é, uma suposta indeterminação informe [eine vermutete formlose $U$ nbestimmtheit]. A matéria é um $x$, porque tudo o que nós conhecemos dela já faz uso da forma, portanto, do elemento subjetivo do conhecimento. $E$ se ainda assim nos é permitido falar de matéria, só então no sentido transcendental como o Correspondens da forma, como o outro da mesma. M as esta matéria transcendental e universal é hic et nunc na sensação concreta o $\mathrm{C}$ orrespondens da forma, isto é, o ordenado [das $\mathrm{G}$ eordnete], e, com isto, o ordenável [das ' 0 rdenbare']. C omo ordenável, a matéria é o múltiplo (M AR KET, 1981, p. 261).

Vinculado à "Estética" e à "Analítica", o múltiplo, no entremeio de ambas, é empregue, a bem dizer, a partir do § 10 da obra, em passagem sintomaticamente complexa:

(...) a lógica transcendental possui diante de si um múltiplo da sensibilidade a priori, apresentado pela estética transcendental, para dar aos conceitos puros do entendimento uma matéria sem a qual seriam sem conteúdo algum e, por conseguinte, inteiramente vazios. 0 ra, espaço e tempo contêm um múltiplo da intuição pura a priori e, não obstante, fazem parte das condições de receptividade da nossa mente, unicamente sob as quais esta pode acolher representações de objetos que portanto também têm sempre que afetar 0 conceito de tais objetos (KANT, 1983, p. 72; id., 1974, A 77 / B 102-3). 
A qui como em toda parte, porém, vigora o pressuposto crítico: " $\mathrm{Na}$ medida em que deve haver razão nas ciências, algo tem que ser conhecido nelas a priori", logo desdobrado na regra metodológica de toda a investigação: " (...) das coisas conhecemos a priori só o que nós mesmos colocamos nelas" (KAN T, 1983, p. 13; id., 1974, B XVIII) . À luz desta orientação geral e em face do conceito de que se trata, a questão de: 0 que seja o múltiplo?, torna-se rigorosamente desproporcional, ele próprio sendo a única identidade a priori possível da matéria. 0 que indagar a respeito dele, pois? Certo é que a questão, qualquer que seja, se referirá, cedo ou tarde, à ordenação da matéria, à unidade sintética do múltiplo em conceitos. $M$ as a postulação deste encargo, admitido o ponto de partida, não traz consigo nenhuma polêmica. $\mathrm{N}$ ão havendo, por conseguinte, meio nenhum de nos referirmos a priori à matéria, senão através de sua multiplicidade suposta, bem como, em seguida, modo nenhum de obter-Ihe a necessária unificação, senão por obra da síntese categorial, a questão a respeito do múltiplo, não mais devendo repetir a impostação metafísica e perder-se nos ardís da qüididade, será a de como seja possível a multiplicidade? Q uæstio iuris, portanto, relativa à legitimidade do emprego do conceito.

0 "múltiplo da intuição pura", diz-nos K ant, é "o primeiro elemento que nos tem que ser dado a priori para o conhecimento de todos os objetos" (KAN T, 1983, p. 73; id., 1974, B 104). M esmo assim, o próprio múltiplo ocorre tanto pura como empiricamente.

D eve-se então falar do múltiplo empírico como se da própria experiência ele assim proviesse ou como se do modo subjetivo de recepção do objeto ele como tal primeiro surgisse? Espaço e tempo representam um objeto já múltiplo-empiricamente dado ou descrevem múltiplo-puramente algo de por inteiro indeterminado?

0 múltiplo espaço-temporal será posto em ação por via do múltiplo empírico ou pelo objeto da afecção, simplesmente? Passiva a sensibilidade a priori, teremos de pressupor que as modificações a atualizar 0 múltiplo puro sejam devidas à múltiplicidade afetante do objeto indeterminado? Com isto, a multiplicidade empírica suposta parecerá exigir uma forma a priori em potência, que, múltipla, transcreva a como tal para o sujeito. Esta seria uma solução de tipo realista, na qual a multiplicidade do dado empírico independeria de seu correspondente puro. Podemos 


\section{8}

presumir tanto assim no objeto? Se, ao contrário, pressupusermos 0 múltiplo puro como fonte da multiplicidade empírica, esta resultará na (múltipla) transcrição espaço-temporal do objeto afetante. Podemos presumir uma tal operação? N ão desembocaria ela no inatismo das A nschauungsformen, configurando assim uma solução de tipo idealista, na qual a multiplicidade (posterior) do dado empírico dependeria por completo da pré-existência do múltiplo a priori? Em ambos os casos, a solução proposta estará assegurada pela realidade do ponto de partida: ou a do elemento empírico, bruto e derradeiro, ou a do puro, fonte única de uma lapidação inevitável.

O s padrões de ambas as alternativas em jogo terão, de fato, sobrevindo desde as primeiras interpretações da C rítica. D a mesma forma, não será por acaso queVaihinger, no centenário da obra, ao considerar a $\mathrm{K}$ antliteratur à época de seu K ommentar, subdivide os assim chamados "opositores" da filosofia crítica em "dogmáticos" e"empiristas" (VAIH IN GER , 1970, vol. 1, p. 14-21). Em verdade recorrente, este modus operandi da história da filosofia tem no caso a ironia de um equilíbrio às avessas. Pois não é o próprio Kant (ele mesmo ou comentado) quem se imaginou a meio passo do empirismo e do idealismo? M as idealistas e empiristas, igualmente em mira, voltam-se agora contra a tentativa de apaziguamento levada a efeito pela $C$ rítica. $N$ as observações a seguir, tratar-se-á de examinar a solução de tipo idealista, a ver se ela não será, preferencialmente, de tipo idealista-crítico, idealista-transcendental.

$\mathrm{N}$ a segunda metade do século XIX e face à emergência do neokantismo, autores a cujas obras se deve boa parte do rigor da análise filológica, histórico-filosófica e crítica dos escritos kantianos conferem destaque ao a priori e à idealidade das formas de intuição.

Em seu K ommentar,Vaihinger, referindo-se à expressão "devem... por si próprios ser claros e certos", presente na C rítica em A 2 e dita a propósito dos" conhecimentos universais", considera-a "uma característica do conceito cartesiano-lockeano de idéias inatas, que no aperfeiçoamento kantiano desta doutrina não cabe mais de modo nenhum".Voca 
bulário à parte, a idéia de um "aperfeiçoamento" da doutrina das idéias inatas é já de antemão polêmica, exigindo clareza a respeito do próprio "conceito cartesiano- lockeano de idéias inatas". Como quer que seja, 0 mesmo Vaihinger, talvez interpretando a "grande luz" de 1769 como resultado da leitura dos $\mathrm{N}$ ouveaux essais de Leibniz, considera, por outro lado, que 0 a priori em $\mathrm{K}$ ant, ao menos na "Estética", "possui grande parentesco com o inato", e que "no essencial é idêntico" a ele (VAIH IN GER , 1970, vol. 2, p. 99-100). Em seu discurso "Sobre o significado e a tarefa da teoria do conhecimento", Eduard Z eller já ecoara a mesma posição a respeito das formas de intuição, afirmando que 0 elemento subjetivo presente em todas as representações faz com que as coisas se dêem a nós do modo como as componham "as formas de intuição e de pensamento que nos são inatas [die uns angeborenen A nschauungsund D enkformen]" (ZELLER , 1877, p. 492). Para ser fiéis à lição da época, no entanto, retornemos a $K$ ant, a ver o que tenha dito o próprio.

Ao final do "Corolário" que encerra a Seção III da "Dissertação de 1770 " , K ant concede algumas linhas à questão do surgimento do espaço e do tempo. Já de saída, vale considerar o modo como ele introduz a reflexão: "Surge, por fim, quase espontaneamente, a questão de saber se ambos os conceitos são inatos ou se são adquiridos" (KAN T, 1985, p. 67-8). A quase-espontaneidade escolar do tema, impondo-Ihe procedência, é contrabalançada pela impostação kantiana, que trata o assunto com a desimportância da hora, em sintonia com o H ume do Tratado, por exemplo, que, ao tocar no assunto, desdenhava: "(...) quando se discutiu se haveria idéias inatas..." (H U M E, 2001, p. 31). Em seguida, como a fixar terminologia e conceito sobre a questão, $\mathrm{K}$ ant salomonicamente conclui:

$\mathrm{N}$ a verdade, 0 conceito de ambos é, sem qualquer dúvida, adquirido;

não certamente abstraído a partir da sensação dos objectos (pois a

sensação dá a matéria, mas não a forma do conhecimento humano), mas sim a partir da própria acção da mente que coordena as suas sensações segundo leis permanentes, como um tipo imutável, e, por isso, deve ser conhecido intuitivamente. Com efeito, as sensações 
despertam este acto da mente, mas não intervêm na intuição, nem existe aqui outra coisa inata a não ser a lei do espírito, segundo a qual ele liga de uma maneira determinada as suas sensações provenientes da presença do objecto (KAN T, 1985, p. 68).

0 interesse maior do filósofo está em descrever a forma particular de aquisição da qual se trata, não em deter-se sobre 0 inato. $M$ ais do que salvaguardá-lo, fundamental e indeterminado que é, a preocupação de Kant se volta para a nova forma de aquisição do espaço e do tempo, cujo conceito parece estar de uma vez por todas definido, mas cuja terminologia só em parte sim, vindo a ganhar inteira expressão num texto de circunstância, em 1790.0 fato de nenhuma alteração a respeito ter ocorrido entre a "D issertação" e a "R esposta a Eberhard" é bastante significativo, dado que as duas décadas transcorridas entre uma e outra coincidem com a maturação e fixação do pensamento crítico.

É assim que, em tom polêmico, Kant assegurará, na R esposta, que:

A 'C rítica' não aceita, em absoluto, representações incriadas ou inatas.

Pertençam à intuição ou aos conceitos do entendimento, ela as considera todas como adquiridas. M as há também uma aquisição originária (tal como se expressam os mestres do direito natural), conseqüentemente, [uma aquisição] também daquilo que antes não existia ainda de modo nenhum, por conseguinte, que não pertencia a coisa nenhuma antes desta ação. Tal é, como afirma a 'C rítica', primeiramente a forma das coisas no espaço e no tempo; em segundo lugar, a unidade sintética do múltiplo em conceitos. Pois nenhum deles é tirado dos objetos por nossa faculdade de conhecimento, como dados em si mesmos neles, mas ocorre a priori a partir de si mesmo. D eve, porém, haver um fundamento para isto no sujeito, que torne possível que as representações nasçam assim e não de outra maneira, e, além disso, [que torne possível que elas] possam ser referidas a objetos que ainda não estão dados - e ao menos este fundamento é inato. (KAN T, 1968, p. 221)

Como se vê, "aquisição originária" é expressão complexa, sorte de híbrido conceitual a incorporar "inato" e "adquirido", ambos os tipos em debate. Expirada a relevância da querela, porém (pela qual nunca houve 
interesse da parte de K ant), os mesmos termos serão mantidos, problema ticamente mantidos ao lado da razão de ser de sua utilização renovada. Para que ocorra a aquisição originária, contudo, é preciso de algo que evoque $o$ elemento ainda ausente. U ma mesma fórmula, utilizada sem diferença por Leibniz e Kant, mas também por D escartes, com alguma variação, recebe idêntica tradução em português, indicando o modo pelo qual - "por ocasião da experiência", ei-la - o processo de conhecimento é desencadeado.

Ainda a respeito do surgimento de espaço e tempo, o $\S 28$ da A ntropologia, em 1798, dirá:

A imaginação... como uma faculdade das intuições também sem a presença do objeto é ou p r o d u t i $v$ a, isto é, uma faculdade da exibição originária... do último, que portanto precede a experiência, ou r e p r o d u t i v a, [isto é, uma faculdade da exibição] derivativa..., que reporta à mente uma intuição empírica antes havida. - As intuições puras do espaço e do tempo pertencem à primeira exibição (...). (KAN T, 1968a, p. 167)

D e sua parte, a própria C rítica não emprega o termo "inato", ainda que, em duas passagens da segunda edição, uma delas comum à primeira, aluda ao tema. Em A 66 / B 91, por meio de vocabulário acentuadamente "inatista", K ant afirma:

Seguiremos... os conceitos puros até seus primeiros germes $\mathrm{e}$ disposições no entendimento humano em que se encontram prontos, até que sejam enfim desenvolvidos por ocasião da experiência e que, libertos das condições empíricas inerentes a eles, sejam apresentados em sua pureza pelo mesmo entendimento. (KAN T, 1983, p. 67; id., 1974, A 66 / B 91)

Já em B 166-7, ao fim da "dedução transcendental", o timbre é indisfarçavelmente outro, e o léxico em uso, tomado de empréstimo à futura "biologia", serve como prova indireta dos (limitados) recursos terminológicos à disposição do autor:

(...) há apenas dois caminhos sobre os quais pode ser pensada uma concordância necessária da experiência com os conceitos de seus objetos: ou a experiência torna possível esses conceitos ou esses 
conceitos tornam possível a experiência. 0 primeiro caso não se verifica com respeito às categorias (e também não com respeito à intuição sensível pura); com efeito, são conceitos a priori, por conseguinte independentes da experiência (a afirmação de uma origem empírica seria uma espécie de generatio aequivoca). Logo, só resta o segundo caso (por assim dizer um sistema da epigênese da razão pura): a saber que as categorias contêm, por parte do entendimento, os fundamentos da possibilidade de toda experiência em geral. (KAN T, 1983, p. 99; id., 1974, B 166-7)

Como quer que seja, o fato é que a explicação acerca da origem das formas de intuição impõe a aquisição originária do múltiplo a priori.

A fastada a procedência da suspeita, espaço e tempo não repisando a prática idealista, quer-se agora conhecer a natureza desta relação obrigatória e única, fértil por excelência. 0 que dão um e outro, espaço e tempo e múltiplo empírico, e no que resulta este consórcio? A sensibilidade pura apreende o objeto indeterminado da intuição empírica por meio do espaço e do tempo, formas exclusivas nas quais o conteúdo das impressões pode ser levado à percepção. 0 conteúdo material - tosco, bruto, indeterminado -, acolhido pelas formas de intuição, é multiplamente disposto, pois as formas que o intuem são por si próprias múltiplas.

Como em muitos outros exemplos, uma mesma palavra em alemão é diferentemente traduzida em português. No caso em pauta, opta-se às vezes por "múltiplo" / "multiplicidade", às vezes por "diverso" / "diversidade". N as traduções francesas e portuguesas, é comum o emprego de "diverso" / "diversidade"; já nas brasileiras, inglesas e italianas, "múltiplo" I "multiplicidade". H averá boas razões que expliquem a preferência por uma ou por outra opção, até mesmo por ambas!

"M últiplo" parece servir melhor às características do espaço e do tempo, ao passo que, "diverso", às peculiaridades do s objetos afetantes. $0 \mathrm{~s}$ primeiros são por si mesmos em princípio inespecíficos em sua multiplicidade originária; já os demais, ao contrário, indefinidamente pormenorizados em sua diversidade (material) pressuposta.

Diria então que a possibilidade de se construir um sem-número de quaisquer figuras por meio do espaço-tempo puros é tributária da multiplicabilidade de ambos, ou seja, é tributária da característica de 
ambos como passíveis de multiplicação, e que a possibilidade de se intuir e acolher um sem-número do que quer que seja por meio das impressões sensíveis é, pelo lado do sujeito, tributária da multiplicabilidade pura do espaço e do tempo, e, pelo lado oposto, da diversificabilidade empírica, ou seja, da característica do conteúdo empírico como passível de diversificação.

Penso então em que a realidade do "múltiplo" ou da "multiplicidade" empírica fosse melhor captada se se dissesse: diverso ou diversidade empírica; em contrapartida, a do "diverso" ou "diversidade" pura, se se dissesse: múltiplo ou multiplicidade pura.

Claro está que o problema do múltiplo e/ ou do diverso toca imedia tamente no da afecção, mas também no do esquematismo, contra cuja doutrina eventualmente se voltariam as mesmas baterias de há pouco. Pois os esquemas para os conceitos sensíveis empíricos poderiam carrear a suspeita de que toda a Schematismuslehre fosse empírico- dependente. N 0 entanto, se a diversificabilidade (derivada) dos esquemas para os conceitos sensíveis empíricos responde à diversificabilidade (original) dos próprios objetos da experiência, ela é antes tributária dos esquemas para as categorias, que determinam o próprio tempo e 0 múltiplo nele originalmente presente. $\mathrm{N}$ uma palavra, os esquemas para os conceitos sensíveis empíricos, em sua multiplicidade determinada, decorrem do puro; já em sua diversidade material pressuposta, do empírico.

Vale ainda ressaltar que, do ponto de vista histórico-filosófico, se com Leibniz é primeiro posta a unicidade da mônada, depois a multiplicidade controlada pelo princípio da apetição, com Kant, para quem, segundo 0 tempo, todo o conhecimento começa com a experiência, primeiro se tem 0 diverso, depois a unidade, pois a irredutibilidade do dado exige que a diversidade que o caracteriza seja "acolhida, perpassada e ligada" para então haver conhecimento.

Por outro lado, as expressões de: "múltiplo da intuição empírica" e "múltiplo da intuição pura a priori" podem tornar-se de algum modo confusas no que se refira aos conceitos de "múltiplo" e "intuição" . Q uer 


\section{4}

se trate do objeto empírico, quer do que se constrói na sensibilidade pura, o objeto intuído é sempre intuído unitariamente. Esta unidade (ou "a unidade dessa intuição a priori" ) "pertence ao espaço e ao tempo, e não ao conceito do entendimento" (KAN T, 1983, p. 96; id., 1974, B 161). Contudo, não me parece haver motivo de espanto na atribuição daquela unidade à "Estética" e não à "Analítica", considerando-se que tal ocorre não por residir na "Estética" a origem da ação de unificar, mas por nela estar a fonte (receptora) do que é unificado. A unidade da intuição serIhe-á portanto concedida, só porque voltada para a unificação do múltiplo. 0 ra, do mesmo modo compreender-se-á a ocorrência de "múltiplo" e "intuição" (que já exige a unidade) numa única fórmula. 0 "múltiplo da intuição" (quer pura, quer empírica) referir-se-á ao modo como seja particularmente caracterizado o conteúdo da intuição ou a multiplicidade do objeto afetante. Trata-se de mostrar que o conteúdo unitariamente intuído é já o resultado de uma síntese anterior que acresce representação a representação. $\mathrm{N}$ a feliz expressão de C ohen:

$R$ eunião e sucessão, tais os dois conteúdos com os quais $K$ ant dotou as formas da sensibilidade. De uma maneira geral, ele designou estas duas espécies de conteúdo sensível com uma expressão que posteriormente voltou-se contra ele: 'o múltiplo da intuição'. Se um conhecimento deve nascer, é preciso que o múltiplo da intuição, a título de condição negativa, Ihe seja 'dado'. Todavia, este múltiplo é múltiplo da intuição sensível; ele não é, pois, dado em todos os sentidos, mas é produzido; ele é a determinação da forma da geometria e das disciplinas matemáticas aparentadas, nas quais é produzido e nas quais se deve poder apresentar tudo o que deve poder tornar-se um objeto de experiência. (COHEN, 2001, p. 245-6)

Assim, o que quer que eu intua, faço-o sempre no espaço e no tempo, formas de intuição em mim. Por conseguinte, todo o intuído é como tal um múltiplo. 0 fato de intuir o que quer que seja como múltiplo é uma característica do meu modo de intuição, do modo de intuir no espaço e no tempo. 0 que me aparece, aparece multiplamente; e multiplamente aparece, porque o que quer que me apareça só pode aparecer assim. $\mathrm{N}$ ão intuo um múltiplo que me seria dado por si como tal, mas intuo multiplamente o "objeto indeterminado de uma intuição empírica". Como 
afirma K ant: "Toda intuição contém em si um múltiplo, que, porém, não seria representado como tal, se a mente, na seqüência das impressões, não distinguisse o tempo de uma [impressão] a outra" (K AN T, 1974,A 99). A ocorrência da afecção não depende do sujeito, mas sim o modo por que o objeto afetante é apreendido. C omo pondera Scaravelli: "a 'sensação' é efeito da 'constituição'; quanto ao seu surgimento, porém, este não é de maneira nenhuma efeito da estrutura da sensibilidade, pois que tal surgimento (mas somente ele) depende da 'afecção' que sobre a sensibilidade é exercida ab extra'" (SC AR AVELLI, 1983, p. 148, n. 8).

N ão se pode então afirmar: 0 "múltiplo" é como tal já dado, mas: algo dado é multiplamente apreendido. Numa palavra, não determino 0 múltiplo dado, mas sim um algo qualquer de multiplamente apreendido nas formas puras de recepção. C onseqüentemente, se a "lógica transcendental possui diante de si um múltiplo da sensibilidade a priori", tal ocorre porque ela própria já o pré-determinou. Isto é: obrigou o conteúdo material a ajustar-se à multiplicidade da apreensão.

C reio agora poder-se concluir - ainda que por meio destas rápidas observações - , que uma solução de tipo "realista", facilitada pela letra da obra, posta de lado por seu espírito, não exige adotar a opção contrária, idealista, também induzida pela letra comum imperfeita, à qual se renunciará, igualmente, em favor da mesma razão. $\mathrm{N}$ em a multiplicidade empírica, dada por si como tal, nem a congenialidade das formas de intuição. D oação de uma diversidade empírica e aquisição originária da multiplicidade pura, cada qual em sua esfera, ambas solidárias em favor da produção do conhecimento, de tal modo que se diga serem elas" autonomias recíprocas".

${ }^{1}$ A s referências ao texto original serão feitas conforme a paginação das edições de 1781 ("A") e 1787 (“B”).

$2 \mathrm{~N}$ o âmbito da primeira C rítica, na“"D edução transcendental dos conceitos puros do entendimento", pode-se ainda encontrar uma outra confirmação deste mesmo pressuposto, em passagem do § 15: “(...) não podemos nos representar nada ligado no objeto sem o termos nós mesmos ligado antes" (KAN T, 1983, p. 84; id., 1974, B 130). 


\section{Referências bibliográficas}

COHEN , H . 2001. La théorie kantienne de l'expérience. Paris: CER F.

HU M E, D. 2001. Tratado da natureza humana. São Paulo : Imprensa O ficial do Estado - Editora da U nesp.

KAN T, I. 1968a. A nthropologie in pragmatischer $H$ insicht. In: $K$ ants W erke. A kademie-Textausgabe. Berlin :Walter de Gruyter.

1968b. Ü ber eine E ntdeckung, nach der alle neue $\mathrm{K}$ ritik der reinen Vernunft durch eine ältere entbehrlich gemacht werden soll. In: $K$ ants W erke. A kademie-Textausgabe. Berlin :Walter de Gruyter.

1974. $K$ ritik der reinen Vernunft. In:W EISC H EDEL, W. Immanuel $K$ ant. Werkausgabe in zwölf Bänden. Frankfurt am M ain : Suhrkamp.

_-- 1983. C rítica da razão pura. 2a. edição. São Paulo: A bril Cultural. 1985. D issertação de 1770 seguida de C arta a M arcus H erz. Lisboa: Imprensa $\mathrm{N}$ acional - C asa da M oeda.

M AR KET, O. 1981. "D as M annigfaltige und die Einbildunskraft". In: A kten des 5 . Internationalen $\mathrm{K}$ ant- $\mathrm{K}$ ongresses. Bonn : Bouvier.

M Ö R CHEN , H . 1970. D ie E inbildungskraft bei K ant. T übingen: M ax $\mathrm{N}$ iemeyer.

SCAR AVELLI, L. 1973. Scritti kantiani. Firenze : La N uova Italia.

VAIH IN GER , H. 1970. K ommentar zu K ants K ritik der reinen Vernunft. 2a. edição. Aalen : ScientiaVerlag.

ZELLER , E. 1877. “Ü ber Bedeutung und Aufgabe der Erkenntnisstheorie". In: id., Vorträge und A bhandlungen. Leipzig : R eisland. 